\title{
Plasma cholinesterase deficiency in a neonate
}

We report a two-day-old infant who had a period of apnoea lasting six hours following the intravenous administration of succinylcholine (Sch). The results of her plasma cholinesterase level and dibucaine number indicate a congenital absence of plasma cholinesterase ( $P C h E)$ enzyme, although both parents and siblings had normal cholinesterase levels and dibucaine numbers. This is believed to be the youngest reported case of prolonged apnoea after the administration of succinylcholine.

Nous rapportons le cas d'un bébé de deux jours qui présente une période d'apnée de six heures après l'administration intraveineuse de succinylcholine. Les résultats du dosage de la cholinestérase plasmatique et de l'épreuve à la dibucaïne montrent une absence congénitale de cholinestérase plasmatique (PChE), malgré des dosage normaux chez les parents et la fratrie. Nous croyons quill s'agit là du plus jeune cas d'apnée prolongée après administration de succinylcholine.

Prolonged apnoea after succinylcholine occurs most commonly due to a genetic variant of cholinesterase. Several case reports have documented succinylcholine-induced prolonged apnoea in infants with the youngest reported case being a three-week-old infant. ${ }^{1-3}$ We report a case of prolonged neuromuscular blockade after succinylcholine administration to a two-day-old infant.

\section{Case report}

A two-day-old, $3.5 \mathrm{~kg}$ neonate presented for awake nasal fibreoptic laryngoscopy and rigid bronchoscopy under anaesthesia for the evaluation of inspiratory stridor. She was the full term product of an uncomplicated pregnancy

\section{Key words}

ANAESTHESIA: paediatric;

ENZYMES: cholinesterase;

NEUROMUSCULAR RELAXANTS: succinylcholine.

From the Department of Anesthesia and Critical Care, Temple University School of Medicine, Philadelphia, Pennsylvania.

The work was done at St. Christopher's Hospital for Children, Philadelphia, PA.

Address correspondence to: Dr. C.A. Pasquariello, Department of Anesthesia and Critical Care, St. Christopher's Hospital for Children, Erie Avenue at Front Street, Philadelphia, PA 19134. born by normal spontaneous vaginal delivery to a gravida 2 para 1 healthy 32-yr-old female. The child was otherwise healthy and the family history is unremarkable. The $\mathrm{SpO}_{2}$ measured with a probe placed on the left thumb, ranged from 80 to $95 \%$ in air. After administration of atropine and oxygen, the patient underwent awake fibreoptic nasal pharyngoscopy. Following the diagnosis of vocal cord paralysis, succinylcholine, $2.0 \mathrm{mg} \cdot \mathrm{kg}^{-1}$, was given $i v$ to facilitate diagnostic rigid bronchoscopy. Maintenance of anaesthesia was provided with an inhaled gas mixture of $1 \%$ halothane in oxygen. At the completion of the $15 \mathrm{~min}$ procedure, halothane was discontinued.

When no movement or ventilatory effort occurred in 10 minutes, peripheral nerve stimulation revealed absence of response to single twitch and tetanic stimuli. Presuming a diagnosis of cholinesterase deficiency, we sedated the child with midazolam $0.1 \mathrm{mg} \cdot \mathrm{kg}^{-1}$ and fentanyl 2 $\mu \mathrm{g} \cdot \mathrm{kg}^{-1}$. Endotracheal intubation was maintained and mechanical ventilation was instituted. Two hours later, spontaneous eye opening and movement appeared. Six hours following succinylcholine, when train-of-four stimulation demonstrated four twitches and sustained tetanus, the trachea was extubated. Cholinesterase activity measured at three days of age was $0.2 \mathrm{U} \cdot \mathrm{ml}^{-1}$ (normal: 3.4-6.5 $\mathrm{U} \cdot \mathrm{ml}^{-1}$ ) and the dibucaine number was $<5 \%$ (normal: $73-90 \%$ ).* Because of the suspicion of plasma cholinesterase deficiency, serum values of plasma cholinesterase and dibucaine numbers were sent on both parents and an older sibling at the same time. Her mother's cholinesterase activity was $3.8 \mathrm{U} \cdot \mathrm{ml}^{-1}$ and dibucaine number $87 \%$. Her father's cholinesterase was $3.8 \mathrm{U} \cdot \mathrm{ml}^{-1}$ and dibucaine number was $84 \%$. Her sister had a cholinesterase activity of $4.2 \mathrm{U} \cdot \mathrm{ml}^{-1}$ and a dibucaine number of $88 \%$.

\section{Discussion}

Prolonged apnoea after neuromuscular blockade can be attributed to a wide variety of contributing factors, especially in the neonate. Our initial differential diagnosis

*The plasma cholinesterase level was measured by the Boehringer Mannheim cholinesterase method at the SmithKline Beecham Clinical Laboratories, Van Nuys, California. This method utilizes acetylthiocholine as the substrate. Fluoride and chloride numbers were not determined. 
included hypothermia, hypoglycaemia, hypocalcaemia, acidosis, hypoxaemia, medication error, and catastrophic neurologic event. ${ }^{4}$ Although each of these was considered and ruled out, the deciding factor was the absence of neuromuscular transmission as determined by the peripheral nerve stimulator.

Pseudocholinesterase is found in most tissues including plasma. The plasma enzyme is synthesized in the liver. The molecular weight of the major isoenzyme of PChE is approximately 360,000 , but there are many minor components that have a lower molecular weight. ${ }^{5} \mathrm{PChE}$ has a half-life in serum of 14 days. ${ }^{6}$ There is negligible enzyme activity of plasma cholinesterase in human colostrum and breast milk for at least the first 22 postpartum days. ${ }^{7}$

Healthy pregnant women, compared with nonpregnant women, have a reduction of $\mathrm{PChE}$ activity during late pregnancy through the early postpartum period ranging from 15 to $33 \%$ below baseline levels. Low cholinesterase values were found in $10 \%$ of patients in late pregnancy and during labour, in $20 \%$ of patients one day postpartum, and in $60 \%$ of patients two days later. These values return to pre-pregnancy levels at approximately six weeks postpartum. In most cases, however, there are no clinical differences in SCh activity and duration of neuromuscular blockade. ${ }^{8}$

The infant less than six months of age has about one half of the PChE activity of an older child or adult. The low level of PChE does not seem to prolong the duration of action of a single dose of $\mathrm{SCh}$ in infants. 9,10

The presence of a genetically determined atypical PChE is often considered only after an otherwise healthy patient experiences prolonged neuromuscular blockade, following a conventional dose of SCh. Approximately $90 \%$ of the population is homozygous for the usual allele of serum PChE and have a normal response to SCh. Approximately 1 in 200-480 patients have a heterozygous expression of atypical pseudocholinesterase activity. ${ }^{5,11}$ These patients manifest a modestly prolonged duration of neuromuscular blockade following a single dose of $\mathrm{SCh}$, and dibucaine inhibits $40-60 \%$ of the enzyme activity. "I

One in $2800-3200$ patients 5,11 is homozygous for atypical PChE. This type of patient has a greatly prolonged neuromuscular block following SCh. Dibucaine inhibits only $20 \%$ of the enzyme activity. The dibucaine number which reflects the quality of the PChE and not the quantity of the enzyme that is in the circulating plasma is normally $73-90 \%$ in all age groups.

In addition to those patients who are homozygous for an abnormal gene of PChE, there are patients who are homozygous for a silent gene for cholinesterase. These patients are a heterogeneous group: some patients possess $2 \%$ of normal activity while others have zero level of
PChE activity. Patients who are heterozygotes for the silent gene have serum PChE levels between $28 \%$ and $114 \%$ of normal. ${ }^{5}$

Our patient demonstrated markedly prolonged paralysis from a single dose of SCh. The results of her PChE level and dibucaine number indicate a congenital absence of plasma cholinesterase enzyme.

Some paediatric anaesthetists may allow newborns, during bronchoscopy, to maintain spontaneous ventilation throughout the procedure. However, the use of a muscle relaxant allows the delivery of a lower halothane concentration and prevents coughing and laryngospasm. ${ }^{12}$

This appears to be the youngest documented case of prolonged apnoea after succinylcholine. The fact that both parents and her sibling displayed normal PChE enzyme activity and normal dibucaine numbers, points to the fact that our patient was homozygous for the silent gene and that both of her parents may have been heterozygous for the normal and the silent gene. Although the use of succinylcholine in children has decreased markedly in present clinical practice, the same problem can occur with mivacurium, a new relaxant also metabolized by pseudocholinesterase. ${ }^{13,14}$ Patients with pseudocholinesterase deficiencies demonstrate prolonged neuromuscular block after the $i v$ administration of mivacurium. ${ }^{13}$

\section{References}

1 Gill RS, O'Connell N, Scott RPF. Reversal of prolonged suxamethonium apnoea with fresh frozen plasma in a 6week-old infant. Anaesthesia 1991; 46: 1036-8.

2 Mehta $Y$, Hole $P$. Suxamethonium apnoea in a 4-monthold twin. Anaesthesia 1987; 42: 868-70.

3 Benzer A. Luz G, Oswald E, Schmoigl C, Menardi $G$ Succinylcholine-induced prolonged apnea in a 3-week-old newborn: treatment with human plasma cholinesterase. Anesth Analg 1992; 74: 137-8.

4 Coté CJ, Todres ID, Ryan JF. Preoperative evaluation of pediatric patients. In: Coté CJ, Ryan JF, Todres ID, Goudsouzian NG (Eds.). A Practice of Anesthesia for Infants and Children, 2nd ed., Philadelphia: W.B. Saunders Company, 1993; 39-54.

5 Lehmann H, Liddell J. The cholinesterase variants. In: Stanbury JB, Wyngaarden JB, Frederickson DS (Eds.). Metabolic Basis of Inherited Disease, New York: McGrawHill, 1972, 1730-6.

6 Stoelting $R K$, Dierdorf $S F, M c$ Cammon RL. Anesthesia and Co-Existing Disease, 2nd Ed., New York: Churchill Livingstone Inc., 1988; 355-92.

7 Mc Cance RA, Hutchinson AO, Dean RFA, Jones PEH. The cholinesterase activity of the serum of newborn animals, and of colostrum. Biochem J 1949; 45: 493-6.

8 Shnider SM. Serum cholinesterase activity during preg- 
nancy, labor and the puerperium. Anesthesiology 1965; 26 : 335-8.

9 Zsigmond EK, Downs JR. Plasma cholinesterase activity in newborns and infants. Can Anaesth Soc J 1971; 18: 278-85.

10 Ecobichon DJ, Stephens DS. Perinatal development of human blood esterases. Clin Pharmacol Ther 1973; 14 : 41-7.

11 Stoelting RK. Pharmacology and Physiology in Anesthetic Practice. Philadelphia: JB Lippincott, 1987; 169-216.

12 Morray JP, Krane EJ. Anesthesia for thoracic surgery. In: Gregory GA (Ed.). Pediatric Anesthesia, 2nd ed., New York: Churchill Livingstone Inc., 1989; 893-960.

13 Qstergaard D, Jensen E, Jensen FS, Viby Mogensen J. The duration of action of mivacurium-induced neuromuscular block in patients homozygous for the atypical plasma cholinesterase gene. Anesthesiology 1991; 75: A774.

14 Petersen RS, Bailey PL, Kalameghan R, Ashwood ER. Prolonged neuromuscular block after mivacurium. Anesth Analg 1993; 76: 194-6. 